\title{
Current Aspects of Prevention of Coal Freezing by Means of Inorganic and Organic Reagents
}

\author{
Ekaterina Shmeltser ${ }^{1}$, Maryna Kormer $^{1 *}$, and Vitalij Lyalyuk ${ }^{1}$ \\ ${ }^{1}$ State University of Economics and Technology, Kryvyi Rih, 50006, Ukraine
}

\begin{abstract}
In the cold season, irregular coal supplies to coke plants are aggravated by the need to heat the coal cars. Thawing of rail cars in garages (enclosures) is the least efficient and most expensive approach. Treatment of the coal concentrates with chemical additives reliably prevents freezing in winter during transit from suppliers to consumers. With a view to finding new reagents for preventing the freezing of coal in winter, the lime, the acetates and chlorides of alkaline-earth and alkaline metals are studied. Attention focuses on their physicochemical characteristics, methods of preparation and of introduction in coal concentrate, and their influence on freezing. The results of studies have shown that the use of organosilicon is more effective use of acetates and chlorides of metals. The high activity of organosilicon substances is explained by their elemental composition and structure of molecules.
\end{abstract}

\section{INRODUCTION}

Among the problems encountered by coke plants in the cold season is freezing of the coal concentrates on transportation, which hinders their discharge from the rail cars. The individual coal particles freeze together and also bond with the floor and walls of the car.

This is not a new problem. It has traditionally been addressed by heating the cars with coal in special garages (enclosures), which consumes considerable quantities of energy. It is much less expensive (by several orders of magnitude) to prevent freezing than to heat the frozen coal.

Freezing of coal is possible not only in northern and eastern Russia and in Kazakhstan, which provide coal concentrates for coke production at PAO ArcelorMittal Krivoi Rog, for example, but also in the relatively mild climate of the Ukraine. Recently, despite global warming, the air temperature in winter has been falling to $-20^{\circ} \mathrm{C}$ or less, which interferes with coal supplies to coke plants on account of the longer time required for sorting of the wagons by coal rank before heating and discharging when the freezing of the coal reaches a depth from $0.25-0.30$ to $0.6-1.0 \mathrm{~m}$.

The freezing of coal is a complex thermophysical process accompanied by the migration of moisture and temperature variation. It depends primarily on the thermal conductivity and specific heat of the coal, the duration of the low ambient temperatures, the moisture content of the coal, its metamorphic stage, the composition of mineral impurities, the granulometric composition, and the hydrophilic properties of the surface. However, the key factor is the moisture content of the charge [1].

The water in the coal charge may be divided into free and bound types, depending on its bonds with the solid particles and mobility. The ratio between the quantity of free and bound water depends on the petrographic characteristics: the metamorphic stage, petrographic composition, and dispersity of the coal [2]. Free moisture, with purely physicomechanical bonds to the coal, is formed at the interface of three phases under the action of capillary forces. Its proper ties do not differ from those of ordinary water and it freezes at around $0^{\circ} \mathrm{C}$. It evaporates at the same rate as pure water [3]. On account of its latent heat, bound water does not freeze even at $-(50-70){ }^{\circ} \mathrm{C}$. The con tent of free water increases with the dispersity of the load, which promotes freezing of the coal.

The moisture content of the coal such that it contains only unfrozen water is regarded as the safe moisture content, whose value depends on the metamorphic stage of the coal. The safe moisture content increases with increase in the yield of volatiles and with decrease in ash content of the fuel. That is because the safe moisture content is less for the coal's mineral compound than for the organic component. Increase in ash content of the coal (increase in the content of clay and other impurities able to form colloidal solutions) accelerates its freezing on transportation and storage [3].

The safe moisture content is highest for low metamorphic coal and declines when the coal reaches intermediate stages of metamorphism. That may be attributed to the different porous structure at the surface of the coal particles in different stages of metamorphism, which are associated with different total internal moisture content; by phase composition of the water at the particle surface; and by the strength of the ice that forms [4]. If the moisture content of the coal is at or below the safe level, freezing of the particles will not occur, and the coal will remain friable at negative temperatures [3].

*Corresponding author: maprina1955@gmail.com 
On freezing, three materials interact in the railroad car: the coal, the material of the car's floor and walls, and the air. The main components of the freezing loads are coal particles, water (in three aggregate states), and the gases between the coal particles. At negative temperatures, the friable charge takes on new factors due to redistribution of the free moisture and its conversion to ice and to the formation of cooled structure and texture. The free moisture is mainly converted to ice layers. In the freezing coal, migration of free moisture to the floor of the car is sharply reduced, on account of ice barriers. The transfer of moisture mainly occurs under the action of the temperature gradient [2].

The influence of moisture on the freezing of coal may be assessed in terms of the effort required to separate the freezing samples at the same negative temperatures. The binding strength of the frozen coal particles increases with increase in moisture content and decrease in temperature.

Since the thermal conductivity of different coal samples fluctuates over a small range $\left(0.63-1.26 \mathrm{~kJ} / \mathrm{hm}{ }^{\circ} \mathrm{C}\right)$, the freezing of the coal pieces to one another begins at the same time as their freezing to the walls of the car [5]. Then, depending on the ambient temperature and the residence time, the freezing process extends in all directions [6]. The binding strength on freezing depends not only on the coal's moisture content and the ambient temperature but also on the material from which the car is made. The force required to separate a coal layer frozen to walls of different materials at $-15^{\circ} \mathrm{C}$ is as follows $\left(\mathrm{kN} / \mathrm{m}^{2}\right)$, according to [3]:

Table 1. Forces of separation of frozen material from different surfaces

\begin{tabular}{|l|c|}
\hline \multicolumn{1}{|c|}{ Material } & Forces of separation, $\mathrm{kN} / \mathrm{m}^{2}$ \\
\hline Steel & 78.4 \\
\hline Wood & 71.5 \\
\hline Aluminum & 32.3 \\
\hline Organic glass & 27.4 \\
\hline Ebonite & 18.6 \\
\hline PVC & 12.7 \\
\hline Fluoroplastic & 12.7 \\
\hline
\end{tabular}

\section{ANALYSIS OF PREVIOUS STUDIES}

Protection against freezing depends on analysis of the responsible factors and study of the heat and mass transfer and the rate of freezing of coal on transportation. At present, we may identify two basic approaches to addressing the problem $[5,6]$ :

1) prevention of freezing;

2) restoration of the frozen coal's friability before or during discharge.

Methods of the first type include drying of the coal, mixing of wet and dry coal, refreezing of the coal, and the application of hydrophobic protective coatings to the coal and the walls of the rail cars.

Methods of the second type include heating of the cars with frozen coal in special garages (enclosures) and mechanical action by drilling, vibration, and agitation machines.
The most promising preventive method is to reduce the pour point of the moisture's active component and reduce the strength of the bonds in the frozen coal. The materials employed should be harmless to the operating staff and the environment, should not cause corrosion of metal components, should not impair coal quality, should not significantly reduce the capacity of the rail car, should not require special storage conditions, and should mix well with coal.

\section{RESULTS OF THE STUDY}

In laboratory research on the freezing of coal concentrate samples from the coal preparation shop in the coke plant at PAO ArcelorMittal Kryvyi Rig, we using the lime, the acetates and chlorides of alkaline-earth and alkaline metals are tested as reagents to prevent freezing of coals.

It is found that $\mathrm{CaO}$ may expediently be used to prevent freezing if its activity is no less than $85-88 \%$ and the ambient temperature is not below - $(15-16){ }^{\circ} \mathrm{C}$ [7]. At lower temperatures, freezing is not prevented by unslaked lime even in quantities of $3-6 \%$ of the mass of coal. Unslaked lime only serves an auxiliary function; it may be used as a mechanical layer between the coal layers.

The positive effect of the use of acetates, formiates, and carbamides can be explained by the impact acetyl radicals on centers of the crystallization in the formation of ice, which ensure that it is loose and weak.

We consider acetates of sodium, potassium, calcium [8]. The acetates of potassium and sodium are mixed with coal in quantities of $1.5,2.0,3.0,4.5,5.5$, and 6.0 wt $\%$. The moisture content of the coal ( $\leq 3 \mathrm{~mm}$ class) is $12 \%$, ash content of coal in the dry state $-11.7 \%$, volatile matter in the dry ash-free state $-25,6 \%$.

In Table 2, we show the results of studies and laboratory data of dependence freezing temperatures of coal from the mass fraction of potassium and sodium acetates added to the coal.

Table 2. Dependence of the freezing point of the coal on the added potassium and sodium acetates

\begin{tabular}{|c|c|c|}
\hline $\begin{array}{c}\text { Added } \\
\text { acetate, } \\
\text { wt } \%\end{array}$ & $\begin{array}{c}\text { Freezing point } \\
\text { with added potassium } \\
\text { acetate, }{ }^{\circ} \mathrm{C}\end{array}$ & $\begin{array}{c}\text { Freezing point } \\
\text { with added sodium } \\
\text { acetate, }{ }^{\circ} \mathrm{C}\end{array}$ \\
\hline 1,5 & $-4,5$ & $-4,3$ \\
\hline 2,0 & $-5,0$ & $-5,2$ \\
\hline 2,5 & $-6,4$ & $-6,8$ \\
\hline 3,0 & $-7,6$ & $-8,0$ \\
\hline 3,5 & $-8,6$ & $-8,5$ \\
\hline 4,8 & $-9,4$ & $-8,6$ \\
\hline 5,5 & $-10,6$ & $-8,7$ \\
\hline 6,0 & $-12,3$ & $-8,7$ \\
\hline
\end{tabular}

Potassium acetate effectively reduces the freezing point of coal. There is a clear dependence of the salt content on the temperature. In contrast to potassium acetate, sodium acetate reduces the freezing point to $8.5^{\circ} \mathrm{C}$, at concentrations no greater than $3.0 \%$. With further increase in its concentration, the freezing point of the coal remains unchanged. 
These reagents are less corrosive and are characterized by lower environmental impact. Metal acetates are safe for most surfaces, including concrete, metal, and wood. They are nontoxic and biodegradable under the action of bacteria. Alkaline-earth metals, in contrast to alkaline metals, are present in fluxes and improve the blast-furnace process. Their addition in salt form to coal does not impair its technological properties. Therefore, we now focus on the use of calcium and magnesium acetates to prevent the freezing of coal [8].

Calcium and magnesium acetates were added to the coal raw materials in various ways:

1.The acetates are mixed with coal of $12 \%$ moisture content in quantities of 1.5, 2.0, 3.0, 4.5, 5.5, and $6.0 \mathrm{wt} \%$;

2.Method of producing calcium and magnesium acetates within the coal mass. To that end, the coal is preliminarily mixed with calcium or magnesium oxide. Then the equivalent quantity of $60 \%$ acetic acid is carefully added to the mixture obtained, in accordance with the reaction

$$
2 \mathrm{CH}_{3} \mathrm{COOH}+\mathrm{CaO} \rightarrow \mathrm{Ca}\left(\mathrm{CH}_{3} \mathrm{COO}\right)_{2}+\mathrm{H}_{2} \mathrm{O}
$$

Since water is liberated by reaction with $60 \%$ acetic acid, we need to calculate the effect on the overall moisture content of the coal. It follows from calculation that, even with $6.0 \%$ salt, the moisture content of the coal is increased by no more than $0.6 \%$.

3. Method of producing calcium and magnesium acetates based on the reaction of the carbonates of these metals with acetic acid by the reaction:

$$
2 \mathrm{CH}_{3} \mathrm{COOH}+\mathrm{CaCO}_{3} \rightarrow \mathrm{Ca}\left(\mathrm{CH}_{3} \mathrm{COO}\right)_{2}+\mathrm{H}_{2} \mathrm{O}+\mathrm{CO}_{2} \uparrow
$$

In contrast to the previous method, carbon dioxide is formed in this case. In the case of careful mixing with acetic acid, the freezing point of the coal remains precisely the same. However, if mixing is minimized so that the gas formed is largely retained within the coal, the freezing point falls. In this case, a weighed sample of coal is divided into five 100 -g portions. Each portion is carefully mixed with calcium or magnesium carbonate, and then built up in layers within a vessel. Each layer is combined with the calculated quantity of acid, without mixing.

Comparison of results indicates that treatment with $5.0 \%$ salt by the proposed third method reduces the freezing point of the coal from to $-14.7^{\circ} \mathrm{C}$ and not at $-13.5^{\circ} \mathrm{C}(1$ and 2 methods) [7].

We now turn to solutions of calcium chloride and magnesium chloride [7, 9].

For coal of moisture content up to $12 \%$, the optimal addition of $\mathrm{CaCl}_{2}$ solution is $1.5-2.0 \% / \mathrm{t}$ of coal. About $30 \%$ of the solution should be mixed with the lower layers of the coal, which freeze more severely; the remainder should be distributed uniformly through the rest of the coal. In Fig. 1, we show laboratory data for calcium chloride. The use of calcium chloride is not advised if the coal will subsequently be subjected to high temperature treatment.

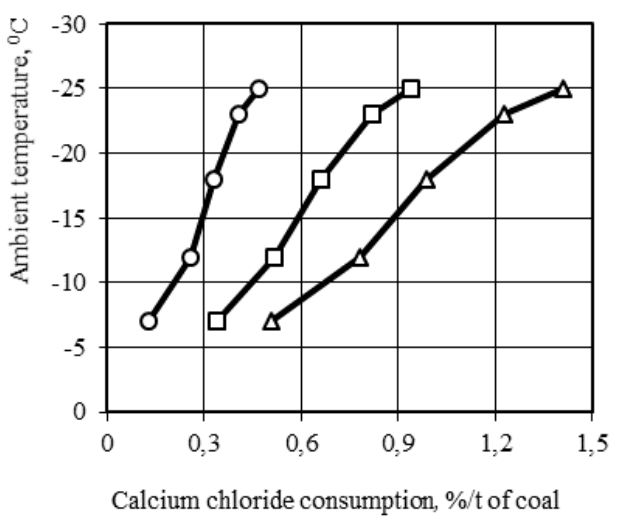

Fig. 1. Calcium chloride consumption to prevent the freezing of coal with $3 \%(1), 6 \%(2)$, and $9 \%$ (3) moisture content

Above $900^{\circ} \mathrm{C}$, the calcium chloride added to the coal begins to break down, with the liberation of chlorine. This process is especially vigorous in the presence of oxides of silicon and aluminum, which act as catalysts. The presence of free chlorine and hot coke may lead to the formation of toxic dioxin. Other problems with calcium chloride are its high cost and corrosive properties.

These concerns do not apply to magnesium chloride, the main component of natural bischofite. It is mined, for example, in the Poltavsk and Chernigovsk deposits in Ukraine. This solution is safe and has medicinal properties. In contrast to calcium chloride, it is not corrosive; in fact, it can slow corrosion rates. In laboratory tests, the quantity of magnesium chloride added is $1-5 \%$ of the coal mass. The moisture content of the coal concentrate employed ( $\leq 3 \mathrm{~mm}$ class) is $12 \%$. The table 3 presents the experimental results.

We see that adding $4-5 \%$ bischofite reduces the freezing temperature of the coal particles to $-16-18{ }^{\circ} \mathrm{C}$. Since the air temperature in the Ukraine rarely reaches $20^{\circ} \mathrm{C}$ in winter, adding $2.5-3 \%$ bischofite to coal transported within the country is best; the effectiveness of mixing must be no less than 96-98\%. As shown by experiments, adding bischofite to coal does not change the packing density of the coal and raises the basicity index by only $0.5 \%$.

In this approach, the moisture between the coal pieces is replaced by a solution with a low eutectic freezing point. The ice formed is characterized by a defective flake structure and consequently is fragile.

Table 3. Freezing temperature of coal treated with bischofite

\begin{tabular}{|c|c|c|}
\hline $\begin{array}{c}\text { Added } \\
\text { bischofite, } \%\end{array}$ & $\begin{array}{c}\text { Calculated } \\
\text { freezing temperature } \\
\text { of bischofite solution, } \\
{ }^{\circ} \mathrm{C}\end{array}$ & $\begin{array}{c}\text { Freezing } \\
\text { temperature of coal } \\
\text { treated } \\
\text { with bischofite, }{ }^{\circ} \mathrm{C}\end{array}$ \\
\hline 1,0 & $-7,3$ & -4 \\
\hline 2,0 & $-11,6$ & -8 \\
\hline 3,0 & $-14,6$ & -10 \\
\hline 4,0 & $-16,3$ & -16 \\
\hline 5,0 & $-19,3$ & -18 \\
\hline
\end{tabular}


Another benefit of magnesium chloride over calcium chloride is that its decomposition at high temperatures does not release chlorine

$$
\begin{aligned}
& \mathrm{MgCl}_{2} \cdot 6 \mathrm{H}_{2} \mathrm{O} \underset{20-60^{\circ} \mathrm{C}}{\longrightarrow} \mathrm{MgCl}_{2} \cdot 4 \mathrm{H}_{2} \mathrm{O} \underset{90^{\circ} \mathrm{C}}{\longrightarrow} \mathrm{MgCl}_{2} \cdot 2 \mathrm{H}_{2} \mathrm{O} \\
& \stackrel{119,5^{\circ} \mathrm{C}}{\longrightarrow} \mathrm{MgCl}_{2} \cdot \mathrm{H}_{2} \mathrm{O} \stackrel{505^{\circ} \mathrm{C}}{\longrightarrow} \mathrm{MgO}+2 \mathrm{HCl}
\end{aligned}
$$

Research shows that coal with low moisture content (no more than 11-12\%) may expediently be treated with an aqueous solution of bischofite, since such treatment will raise the coal's moisture content.

Comparison of protective additives shows that sodium chloride is active to $-10^{\circ} \mathrm{C}$, calcium chloride to $10-16{ }^{\circ} \mathrm{C}$, and magnesium chloride to $-16-18^{\circ} \mathrm{C}$.

The chloride consumption depends on the coal's size class, as is clear from the dependence of the degree of freezing on the moisture content (Table 3 ).

With increase in size class, as we see in Table 3 , the chloride consumption falls. Thus, the calcium chloride consumption declines from 9.2 to $5.3 \mathrm{~g} / \mathrm{kg}$ of coal at $5^{\circ} \mathrm{C}$, from 15.3 to $8.4 \mathrm{~g} / \mathrm{kg}$ at $-10^{\circ} \mathrm{C}$, and from 18.3 to $12.3 \mathrm{~g} / \mathrm{kg}$ at $-15^{\circ} \mathrm{C}$.

Analogous results are obtained for magnesium chloride. Its consumption declines from 6.2 to $3.8 \mathrm{~g} / \mathrm{kg}$ of coal at $-5^{\circ} \mathrm{C}$, from 10.5 to $5.5 \mathrm{~g} / \mathrm{kg}$ of coal at $-10^{\circ} \mathrm{C}$, and from 15.6 to $10.8 \mathrm{~g} / \mathrm{kg}$ of coal at $-15^{\circ} \mathrm{C}$.

Note also that the consumption of calcium chloride practically doubles with decrease in temperature from -5 to $-15^{\circ} \mathrm{C}$ for all size classes: from 9.2 to $18.3 \mathrm{~g} / \mathrm{kg}$ for the $\leq 3 \mathrm{~mm}$ class; from 7.4 to $14.2 \mathrm{~g} / \mathrm{kg}$ for the $3-7 \mathrm{~mm}$ class; and from 5.3 to $12.3 \mathrm{~g} / \mathrm{kg}$ for the $7-15 \mathrm{~mm}$ class. In the same conditions, the consumption of magnesium chloride increases from 6.2 to $15.6 \mathrm{~g} / \mathrm{kg}$ for the $\leq 3 \mathrm{~mm}$ class; from 5.4 to $13.5 \mathrm{~g} / \mathrm{kg}$ for the $3-7 \mathrm{~mm}$ class; and from 2.3 to $10.8 \mathrm{~g} / \mathrm{kg}$ for the $7-15 \mathrm{~mm}$ class. The magnesium chloride consumption is less than the calcium chloride consumption [9].

Table 4. Consumption of calcium chloride and magnesium chloride to prevent freezing

\begin{tabular}{|c|c|c|c|c|c|c|}
\hline \multirow{3}{*}{$\begin{array}{c}\text { Size } \\
\text { class, } \\
\mathrm{mm}\end{array}$} & \multicolumn{7}{|c|}{ Chloride consumption, g/kg of coal } \\
\cline { 2 - 7 } & $\mathrm{CaCl}_{2}$ & $\mathrm{MgCl}_{2}$ & $\mathrm{CaCl}_{2}$ & $\mathrm{MgCl}_{2}$ & $\mathrm{CaCl}_{2}$ & $\mathrm{MgCl}_{2}$ \\
\cline { 2 - 7 } & \multicolumn{2}{|c|}{$\mathrm{at}^{\circ} \mathrm{C}$} & \multicolumn{2}{|c|}{ at $-10^{\circ} \mathrm{C}$} & at $-15^{\circ} \mathrm{C}$ \\
\hline $0-3$ & 9,2 & 6,2 & 15,3 & 10,5 & 18,3 & 15,6 \\
\hline $3-7$ & 7,4 & 5,4 & 10,7 & 8,6 & 14,2 & 13,5 \\
\hline $7-15$ & 5,3 & 3,8 & 8,4 & 5,5 & 12,3 & 10,8 \\
\hline
\end{tabular}

As is evident from Table 4, treating only the $\leq 3 \mathrm{~mm}$ class increases the chloride consumption. Therefore, to prevent freezing, careful mixing of all the coal with reagent is expedient, without division into size classes

But it should be noted that it is advisable to treat with bischofite aqueous solution only coal with low humidity, because when processing coal with an aqueous solution of bischofite increases its humidity. The ultimate increase of coal humidity is $10-12 \%$. Within this range, when the temperature drops below minus $15^{\circ} \mathrm{C}$, the coal will freeze. At lower air temperatures, deep freezing of coal should be expected. The search for the most effective chemical preventive agent to prevent the freezing of coal concentrates in winter at very low temperatures (below minus $18{ }^{\circ} \mathrm{C}$ ) during transportation from the supplier (coal processing plants) to coke plants showed that these requirements are satisfied when using silicone polymer.

Table 5. Consumption of magnesium chloride in treating the $\leq 3 \mathrm{~mm}$ class [9]

\begin{tabular}{|c|c|c|c|}
\hline \multirow{2}{*}{$\begin{array}{c}\text { Content } \\
\text { of } \leq 3 \mathrm{~mm} \\
\text { class, } \%\end{array}$} & \multicolumn{3}{|c|}{$\mathrm{MgCl}_{2}$ consumption, $\mathrm{g} / \mathrm{kg}$ of coal } \\
\cline { 2 - 4 } & at $-5^{\circ} \mathrm{C}$ & at $-10{ }^{\circ} \mathrm{C}$ & at $-15{ }^{\circ} \mathrm{C}$ \\
\hline 50 & 8,2 & 11,4 & 16,8 \\
\hline 70 & 12,4 & 17,4 & 21,6 \\
\hline 80 & 16,2 & 22,1 & 26,6 \\
\hline 90 & 18,7 & 26,5 & 30,5 \\
\hline
\end{tabular}

Molecules of organosilicon compounds combine in part the structure of polymeric inorganic and organic molecules. The basis of their molecules is the siloxane skeleton - a chain of alternating atoms of silicon and oxygen. Other silicon bonds are compensated by organic radicals or groups of atoms [10].

The peculiarity of the structure is associated with the unusual properties of these polymers, which combine the stability of these compounds to the action of low temperatures. Organosilicone liquid polymers can be obtained with a freezing temperature of minus $130^{\circ} \mathrm{C}$ or even lower (fig. 2).<smiles>[R][Si]([R])([R])O[Si]([R])([R])OC</smiles>

Fig. 2. The formula of organosilicone

A valuable property of silicone liquids is the weak dependence of their viscosity on temperature. Thus, as the temperature decreases, the viscosity of the organosilicon compounds increases to a lesser extent than for petroleum oils. This makes it easier to apply to the surface of a metal wagon and mix with coal [6].

For polysiloxanes, low freezing temperatures and chemical inertness to metals are typical. The flammability of organosilicon liquids is much lower than that of organic compounds. The final combustion products are carbon dioxide, water and silica as a fine powder. Polysiloxane fluids do not irritate the skin and eyes.

Thus, the most valuable technical properties of organosilicon liquids are determined by their physical and chemical properties: low pour point (minus 70 to minus 140 ${ }^{\circ} \mathrm{C}$ ), low viscosity dependence on temperature (multiplicity of viscosity change is 5-10 times in the interval temperature temps from -50 to $+50^{\circ} \mathrm{C}$ ) [6].

Emulsions of silicone polymers are stable structures of the type «oil in water». Due to the fact that it is practically more convenient to use aqueous emulsions of silicone liquids instead of their solutions in organic solvents, the industry produces $30-70 \%$ silicone emulsions. These emulsions are easily diluted with water and used in 5-10\% concentration. In commercial form, the emulsions are a white mass of creamy consistency.

Molecules of organosilicon compounds contain an oxygen atom, so the electron density at oxygen atoms is localized. As a result, the reagents can specifically interact with the sorption-active centers of the coal surface bearing a positive charge (protonated hydrogen atoms of phenolic, 
carboxyl groups in macromolecules of organic mass of coal) according to the scheme (fig.3):

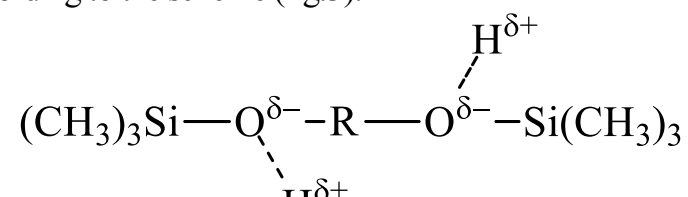

where $\mathrm{R}$ - alkyl radical

Fig. 3. Scheme the interactions of protonated hydrogen atoms of phenolic, carboxyl groups in macromolecules organic mass of coal

Molecules of oxygen-containing organosilicon compounds also contain hydrocarbon radicals that can interact with the apolar centers of the coal surface due to Van der Waals intermolecular forces. Therefore, when adsorbed on the coal surface, molecules of organosilicon exhibit both specific (hydrogen bonds) and universal nonspecific intermolecular forces of interaction with positive parts of the coal surface. This determines their high adsorption on the coal surface.

If the solution or emulsion is mixed with coal, these atoms or groups are reacted with the organic mass of the coal and water hydrate. Organosilicone bonds - Si - O $\mathrm{Si}-\mathrm{O}$-, which provide physical and chemical interaction with the coal facing the surface, and organogenic groups framing the silicon atom in the opposite direction outwards. The orientation of organosilicon bonds and hydrocarbon radicals when applied to the surface can be schematically represented Fig.2.

Organosilicon compounds, when applied to a coal surface, react with water approximately molecule to molecule. The films of organosilicon compounds are very thin. The thickness of the film, which is calculated by the material flow and film weight, assuming that its density is equal to one, is $0.1 \cdot 10^{-6}-2.5 \cdot 10^{-5}$. The film on the surface is invisible, does not wear away when rubbed, does not wash off with water, is stable over a wide temperature range (from -200 to $+300{ }^{\circ} \mathrm{C}$ ). Polymeric silicones on the surface of coal, even in small quantities, provide a great water repellent effect [10].

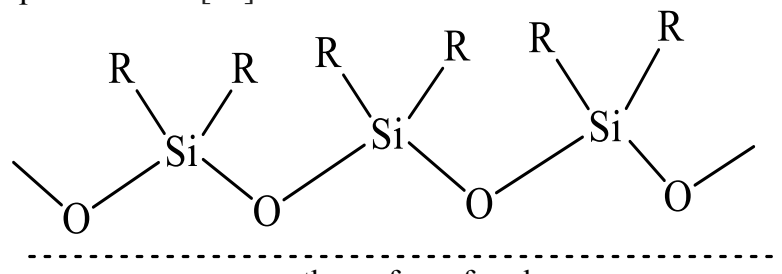

the surface of coal

Fig. 4. Orientation of organosilicon bonds and hydrocarbon radicals on the coal surface

For the experiment, a sample of coal weighing $500 \mathrm{~g}$ was taken, the moisture content of the coal was $12 \%$, the size class was $0-3 \mathrm{~mm}$. The coals were carefully treated with an emulsion. Next, the processed coal was loaded into a metal tank with a diameter of $50 \mathrm{~mm}$, height $50 \mathrm{~mm}$, without bottom and cover. This metal container was placed in the freezer and kept at a predetermined temperature for 24 hours. Then the tank was turned over, and the coal that was poured was weighed. The degree of freezing was thus determined. The study used an organosilicon fluid GKZh-94, which is a colorless slightly yellow liquid. Density $-0,996-1,003 \mathrm{~g} / \mathrm{cm}^{3}$; freezing temperature $-50^{\circ} \mathrm{C} ; \mathrm{pH}$ not less than 6 . In water it is insoluble, but well forms an emulsion, corrosion inactive, does not emit harmful vapors and gases, weatherproof [11].

The organosilicon additive was used as 5 and $10 \%$ aqueous emulsions. The emulsion was thoroughly stirred with charcoal for 3-5 minutes. The amount of emulsion was changed from 4 to $40 \mathrm{~g}$ per $1 \mathrm{~kg}$ of coal. The concentration of the emulsion was 5 and $10 \%$. The results of the experiment are shown in Table 6 .

Studies have also been conducted to identify consumption rates of known and claimed prophylactic agents to prevent freezing of coal with a moisture content of $12 \%$ (Table 7) [11].

The analysis of these tables shows that the organosilicon emulsions reduce the freezing point well, and when compared with salts it can be seen that the consumption of the organosilicon emulsion in comparison with the consumption of calcium chloride, magnesium and potassium acetate is lower.

Table 6. The degree of freezing of the treated coal GCZh-94 emulsion at minus $15^{\circ} \mathrm{C}$

\begin{tabular}{|c|c|c|c|}
\hline $\begin{array}{c}\text { Quantity of } \\
\text { GCZh-94, } \\
\mathrm{g} / \mathrm{kg}\end{array}$ & $\begin{array}{c}\text { Mass of } \\
\text { spilled } \\
\text { coal, g }\end{array}$ & $\begin{array}{c}\text { Variation } \\
\text { of mass, } \mathrm{g}\end{array}$ & $\begin{array}{c}\text { Degree of } \\
\text { freezing, } \%\end{array}$ \\
\hline \multicolumn{4}{|c|}{$5 \%$ emulsion } \\
\hline 4 & 150 & 350 & 70 \\
\hline 8 & 170 & 330 & 66 \\
\hline 12 & 190 & 310 & 62 \\
\hline 16 & 220 & 280 & 56 \\
\hline 20 & 260 & 240 & 48 \\
\hline 24 & 290 & 210 & 42 \\
\hline 28 & 310 & 190 & 38 \\
\hline 32 & 390 & 110 & 22 \\
\hline 36 & 450 & 50 & 10 \\
\hline 40 & 490 & 10 & 2 \\
\hline \multicolumn{5}{|c|}{$10 \%$ emulsion } \\
\hline 4 & 200 & 300 & 60 \\
\hline 8 & 220 & 280 & 56 \\
\hline 12 & 250 & 250 & 50 \\
\hline 16 & 270 & 230 & 46 \\
\hline 20 & 290 & 210 & 42 \\
\hline 24 & 360 & 140 & 28 \\
\hline 28 & 400 & 100 & 20 \\
\hline 32 & 420 & 80 & 16 \\
\hline 36 & 480 & 20 & 4 \\
\hline 40 & 500 & 0 & 0 \\
\hline
\end{tabular}

Table 7. Dependence of the freezing point of the coal with a moisture content of $12 \%$ added of prophylactic agents

\begin{tabular}{|c|c|c|c|c|}
\hline $\begin{array}{c}\text { Freezing } \\
\text { point of } \\
\text { sample, } \\
{ }^{\circ} \mathrm{C}\end{array}$ & \multicolumn{4}{|c|}{ Added of prophylactic agents, wt \% } \\
\cline { 2 - 5 } & $\mathrm{CaCl}_{2}$ & $\mathrm{MgCl}_{2}$ & $\mathrm{CH}_{3} \mathrm{COOK}$ & $\begin{array}{c}10 \% \\
\mathrm{GCZh}- \\
94\end{array}$ \\
\hline-15 & 5,0 & 4,6 & 4,0 & 3,6 \\
\hline
\end{tabular}

The successful use of chemical reagents additives depends on the effectiveness of their mixing with coal, with must be at least 96-98\%. At various times, coke plants have used plate, blade, beater, drum, screw, and disintegration units for batch mixing. 
We propose [7] a system of rotor type for final mixing of the coal batch with any protective additive. The mixer (Figs. 5 and 6) is mounted above a conveyer belt, so that its rotors fit within the cross sections formed by the ribbed conveyer belt, with a gap between the plane of the belt and the rotor blades.

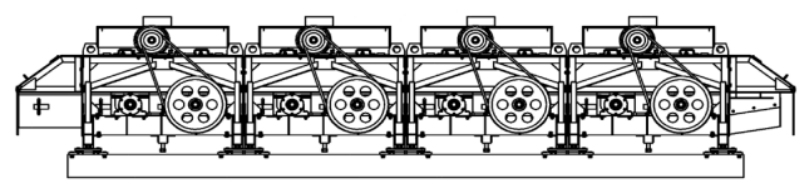

Fig. 5. Four-section rotary mixer: (1) mixer section; (2) support; (3) adjustable screws; (4) V-belt transmission; (5) electric motor; $(6,8)$ shielded input and output sections; $(7)$ seal.

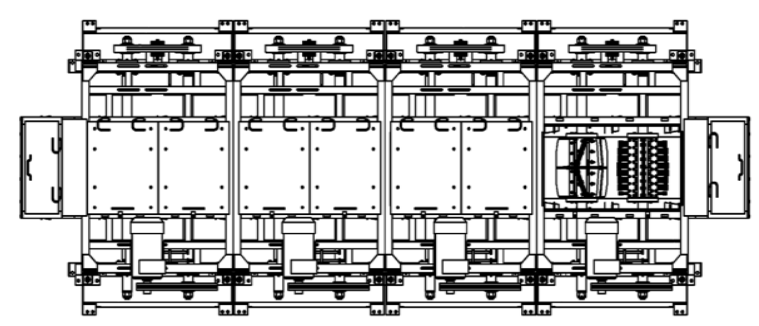

Fig. 6. Four-section rotary mixer (top view): (1) electric motor; (2) cable rotor; (3) blade rotor; (4) V-belt transmission; (5) tension roller

The rotors (Figs. 7 and 8 ) are responsible for the mixing. Each section of the mixer contains two types of rotors: one with regular blades and one with cable elements. The rotors turn in the same direction as the coal batch moves through the mixer.

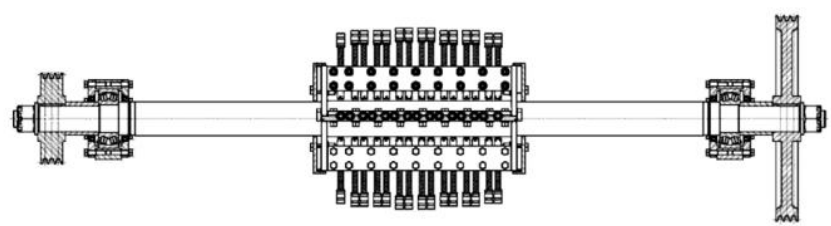

Fig. 7. Cable rotor of mixer: (1) shaft; (2) drum; (3) removable blades; (4) cable elements; (5) lock.

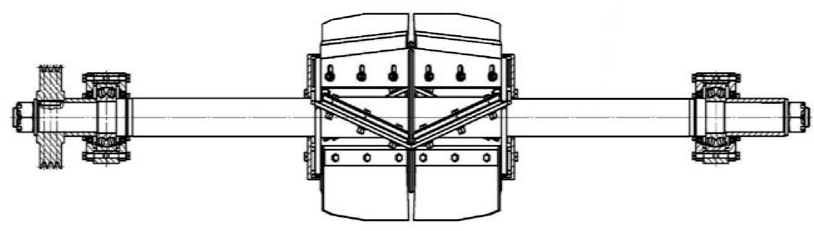

Fig. 8. Blade rotor of mixer: (1) shaft; (2) drum; (3) removable blades; (4) flexible blade elements; (5) lock

As the coal batch moves over the belt, it is acted on by the rotor blades and mixed with the protective additives. The characteristics of the SR2520 $\times 1.0$ mixer are as follows:
Table 8. The characteristics of the SR2520 $\times 1.0$ mixer

\begin{tabular}{|l|c|}
\hline \multicolumn{1}{|c|}{ Parameter } & Value \\
\hline Width of conveyer belt, mm & 1000 \\
\hline Number of sections & 2 \\
\hline Rotor diameter, mm & 520 \\
\hline Rotor speed, rpm & 250 \\
\hline Length of rollers in horizontal support, $\mathrm{mm}$ & 410 \\
\hline Conveyer slope, deg & 0 \\
\hline Rated power, $\mathrm{kW}$ & 15 \\
\hline Power of a single electric motor, $\mathrm{kW}$ & 7.5 \\
\hline Number of motors & 2 \\
\hline
\end{tabular}

\section{Conclusions}

The treatment of coal concentrates with protective additives may reliably prevent freezing on transportation from suppliers to consumers in winter. The coal may easily be discharged from the rail cars, without large energy expenditures to heat the cars in special garages (enclosures). The increase in coal cost due to its treatment with protective additives by the supplier is more than compensated by the savings at the consumer, where no heating is required. Also, the coal does not need to be crushed by heavy duty machines, which usually results in excessive reduction in piece size and increase in leanness of the batch, especially in the case of valuable coal ranks, and sharply impairs coke quality.

Thus, the proposed method not only prevents the concentration of coal concentrates in winter during their transportation from the manufacturer to the coke plant, but also reduces the cost of coke by reducing the cost of defrosting (in greenhouses) and unloading coal, to prevent the corrosion of cars and equipment of coalpreparation shops of coke-chemical plants. Organosilicon compounds are less toxic. The use of organosilicon is more effective than the use of acetates and chlorides of metals. The high activity of organosilicon substances is explained by their elemental composition and structure of molecules.

\section{References}

1. S.F. Matasov, L.M. Kurtunov and A.S. Khorunzhii "Bor'ba so smerzaemost'yu pri perevozke po zheleznymdorogam" (Prevention of freezing in railroad transportation), Moscow: Metallurgiya, (1974)

2. M.I. Lepnev and E.P. Severinov. "Gruzy i moroz (Freezing of cargo), Moscow: Transport, (1988)

3. N.M. Mikhailov and A.T. Sharkov "Fizicheskie svoistva topliva i bor'ba s zatrudeniyami na toplivopodache elektrostantsii" (Physical properties of fuel and prevention o supply problems at power stations), Moscow: Energiya, (1974)

4. I.V. Eremin, V.V. Lebedev and D.A. Tsikarov "Petrografiya i fizicheskie svoistva uglei" (Petrography and physical properties of coal), Moscow: Nedra, (1980)

5. N.N. Kozhevnikov, V.I. Popov. "Prognozirovanie protsessov promerzaniya v spuchykh materialakh pri zheleznodorozhnykh perevozkakh" (Predicting 
freezing in friable materials during rail transportation), Novosibirsk: Nauka, (1978)

6. V.E. Parunakyan, R.I. Sinyavskaya “Bor'ba s prilipaniem i primerzaniem gornoi massy $\mathrm{k}$ rabochim poverkhnostyam transportnogo oborudovaniya na kar'erakh" (Preventing the freezing of cargo to the working surfaces of vehicles in mines), Moscow: Nedra, (1975)

7. A.D. Uchitel, M.V. Kormer, V.P. Lyalyuk, E.O. Shmeltser "Transportation of Coal Concentrates at Negative Ambient Temperatures" Coke and Chemistry, 56, № 5, 167-172 (2013)

8. E.O. Shmeltser, M.V. Kormer, V.P. Lyalyuk et al "Prevention of coal freezing by means of acetates" Coke and Chemistry, 59, № 4, 132-136 (2016)

9. M.V. Kormer, V.P. Lyalyuk, E.O. Shmeltser, A.D. Uchitel et al "Dependens of coals freezing point on its granulometric composition" Coke and Chemistry, 58, № 1, 9-14 (2015)

10. M.V. Sobalevskiy, O.A. Muzovskaya, G.S.

Popeleva "Svoystva i primeneniye kremneorganicheskikh produktov", M.: Khimiya, (1975)

11. M.V. Kormer, V.P. Lyalyuk, E.O. Shmeltser, D.A. Kassim, I.A. Lyakhova. UA Patent 113500: MPK (2006.01) C09K 3/18, Byull. Izobret., № 2 (2017) 